NBER WORKING PAPER SERIES

\title{
UNOBSERVABLES, PREGNANCY RESOLUTIONS, AND BIRTHWEIGHT PRODUCTION FUNCTIONS \\ IN NEW YORK CITY
}

Michael Grossman

Theodore J. Joyce

\author{
Working Paper No. 2746
}

\author{
NATIONAL BUREAU OF ECONOMIC RESEARCH \\ 1050 Massachusetts Avenue \\ Cambridge, MA 02138 \\ October 1988
}

This research is part of NBER's program in Health Economics. Any opinions expressed are those of the authors not those of the National Bureau of Economic Research. 


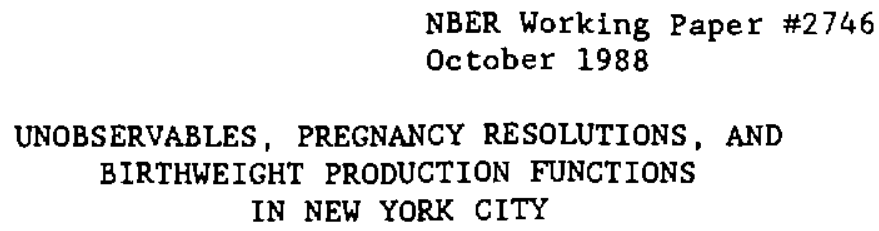

\section{$\underline{\text { ABSTRACT }}$}

This paper makes contributions to the estimation of health production functions and the economics of fertility control. We present the first infant health production functions that simultaneously control for selfselection in the resolution of pregnancies as live births or induced abortions and in the use of prenatal medical care services. We also incorporate the decision of a pregnant woman to give birth or obtain an abortion into economic models of fertility control and use information conveyed by this decision to refine estimates of infant health production functions and demand functions for prenatal medical care.

Michael Grossman Department of Economics City University of New York Graduate School

$33 \mathrm{~W}$. 42nd street New York, NY 10036
Theodore Joyce

Department of Health Care Administration

Baruch College

City University of New York

17 Lexington Avenue

New York, NY 10010 
UNOBSERVABLES, PREGNANCY RESOLUTIONS, AND BIRTHWEIGHT PRODUCTION FUNCTIONS IN NEW YORK CITY

Michael Grossman and Theodore J. Joyce*

This paper makes contributions to two areas of investigation within the context of the household production function approach to consumer behavior (Becker 1965; Michael and Becker 1973): the estimation of health production functions and the economics of fertility control. In the former area we present the first infant health production functions that simultaneously control for self-selection (correlations between unobserved variables and observed outcomes) in the resolution of pregnancies as live births or induced abortions and in the use of prenatal medical care services. In the latter area we incorporate the decision of a pregnant woman to give birth or obtain an abortion into economic models of fertility control and use information conveyed by this decision to refine estimates of infant health production functions and demand functions for prenatal medical care.

The concept of a health production function, originally developed by Grossman (1972), has been widely accepted and fruitfully applied. Yet, until recently, researchers have tended to emphasize reduced form as opposed to structural estimates. The reasoning was clear. Unobserved biological factors such as an individual's exogenous health endowment and hard-to-measure endogenous inputs such as nutrition, exercise, and the avoidance of stress can play major roles in the determination of health outcomes. If an individual's behavior is shaped in part by knowledge of his or her endowment or if the unmeasured endogenous inputs are correlated with the included inputs, then estimates of the health technology will be biased.

Recent work on the economic analysis of infant health (measured by 
birthweight or survival) by Rosenzweig and Schultz (1982, 1983a, 1983b, forthcoming a, forthcoming b); Corman, Joyce, and Grossman (1987); and Joyce (1987) has emphasized structural estimates of the health technology. In these studies two-stage least squares has been applied to control for the adverse selection of health inputs. In particular, Rosenzweig and Schultz have argued that women who anticipate a problematic birth based on conditions unknown to the researcher seek out more remedial care while women with positive expectations seek out less. Consequently, the association between such variables as early prenatal medical care and birthweight is understated when measured by direct correlation measures.

Adverse selection in input use is, however, only one source of bias. In the epidemiological literature researchers have argued that favorable selection may be a more serious source of confounding (Gortmaker 1979; Institute of Medicine 1985). The efficacy of prenatal care, for example, may be seriously overstated if early care is but one form of healthy behavior. Pregnant women who initiate care promptly may eat more nutritiously, suffer less stress, engage in the appropriate exercise, and use less drugs and other potentially harmful substances than women who begin care late. The omission of these hard-to-measure inputs tends to overestimate the impact of early prenatal care on birthweight.

Moreover, the resolution of a pregnancy itself may be characterized by self-selection. With regard to this outcome, selection is favorable if women whose fetuses have poor health endowments are more likely to obtain an abortion or if women who desire to make relatively large investments in their infants are more likely to give birth. On the other hand, selection 
is adverse if women who make relatively small investments are more likely to give birth.

The use of an instrumental variable approach to correct for selfselection in input use presupposes that this decision is characterized by adverse selection ${ }^{1}$ and ignores the problem of self-selection in the resolution of pregnancies. In this paper we approach the problem differently and somewhat more generally. Following Heckman (1979), we treat the estimation of infant health production functions and prenatal medical care demand functions as a general problem in self-selection. Specifically, we test whether women who give birth represent a random draw from the population of women who become pregnant. The widespread use of induced abortion since its legalization by the Supreme Court in 1973 has permitted much greater choice in the number and timing of births. In the United States in 1983, 30 percent of all pregnancies (1ive births plus induced abortions) were terminated by induced abortions (Bureau of the Census 1986). Thus, the extent to which a failure to incorporate the choice-based nature of micro vital records into estimates of infant health production functions may bias the parameters of this function is potentially large. It is our specific hypothesis that the unobserved factors that impact on the decision to give birth not only affect pregnancy outcomes but also condition the behavior of women who choose to give birth during pregnancy as we 11 .

Our study is based on a cohort of pregnant women in New York City in 1984. In that year 45 percent of a 11 pregnancies to New York City residents ended in induced abortions. We estimate a three equation model. The first equation is the probability of giving birth, given that a woman is pregnant. 
With this as our criteria equation, we test for self-selection in the infant health (measured by birthweight) production function and in the prenatal medical care demand function. Empirically, our estimates differ from those obtained by Rosenzweig and Schultz (1982, 1983b, forthcoming a, forthcoming b) because they use micro vital records on live births alone. Not only does our methodology obviate the need to assert a priori whether adverse or favorable selection is dominant, but the sign pattern of the residual covariances indicates which type of selection characterizes both the decision to give birth and the decision to initiate prenatal care promptly.

Since our framework includes an implicit equation for the probability of becoming pregnant, we incorporate induced abortion as an alternative to traditional methods of contraception into economic models of fertility control (for example, Michael and Willis 1975; Heckman and Willis 1975; Hotz and Miller 1988).2 These models emphasize the use of contraception to reduce the uncertainty associated with the number and timing of births. Induced abortion eliminates much of this uncertainty at a positive price. By assuming that the prices of contraception and abortion have unmeasured components that vary among women, we enrich the theoretical literature on the optimal number and quality of children (for example, Becker and Lewis 1973; Willis 1973) and gain a better understanding of the earliest indicator of child quality -- infant health -- and the resources allocated to its production. In particular, we show that the prices of contraception and abortion, as well as the health endowment of the fetus, simultaneously influence decisions with regard to pregnancy resolutions and input selection. 


\section{Analytical Framework}

Rosenzweig and Schultz (1982, 1983a, 1983b, for thcoming a, forthcoming b); Corman and Grossman (1985); Corman, Joyce, and Grossman (1987); and. Joyce (1987) have generated and estimated birth outcome production functions and input and output demand functions for infant health in the context of a static economic model of the family and household production. It is assumed that the parents' utility function (or the mother's utility function in families with no father) depends on their own consumption, the number of births, and the survival probability of each birth (which does not vary among births in a given family). The last variable is governed to a large extent by birthweight. Both the number of births and the outcome of each birth are endogenous variables. In particular, the birthweight production function depends upon endogenous inputs including the quantity and quality of medical care, the own time of the mother, and such healthy behaviors as proper diet, appropriate exercise, and the avoidance of stress. In addition, the production function is affected by the reproductive efficiency of the mother, including the unobserved biologically endowed probability that her infant will survive the first month of life, and other aspects of her efficiency in household production.

Maximization of the utility function subject to production and resource constraints generates a demand function for birthweight in which this outcome is related to input prices (whose indirect cost components are negatively related to input availabilityl, efficiency, income, and tastes. The interaction between the birthweight demand and production functions determines demand functions for prenatal care and other endogenous inputs. These 
demand functions depend on the same set of variables as the demand function for birthweight.

To introduce the decision of a pregnant woman to give birth or obtain an abortion into the above model, note that a dynamic version of it implies an optimal number of children for the $i$ th woman in year $t\left(c_{i t}^{\star}\right)$. If $c_{i t}$ is the actual number of children that a pregnant woman will have in year $t$ in the absence of an abortion (parity plus one), then she will give birth provided $\pi_{i t}=C_{i t}-C_{i t} \geqslant 0$ and will abort provided $\pi_{i t}<0$.

Equations for the probability of a birth $\left(\pi_{i}\right)$, the production function of birthweight $\left(b_{i}\right)$, and the demand for prenatal medical care $\left(m_{j}\right)$ now can be specified. For convenience, the time subscripts and the intercepts are suppressed. The birth probability function is assumed to be linear, although later a probit specification will be used. The three equations are

$$
\begin{aligned}
& \pi_{i}=\alpha_{1} z_{i}+u_{1 i}, u_{1 i}=\alpha_{2} c_{i}+\alpha_{3} a_{i}+\alpha_{4} e_{i} \\
& b_{i}=\beta_{1} x_{i}+\beta_{2} m_{i}+u_{2 i}, u_{2 i}=\beta_{3} q_{i}+\beta_{4} e_{i} \\
& m_{i}=\gamma_{1} y_{i}+u_{3 i}, u_{3 i}=\gamma_{2} c_{i}+\gamma_{3} a_{i}+\gamma_{4} e_{i}
\end{aligned}
$$

In this system of equations, $z_{i}, x_{i}, y_{i}, c_{i}, a_{i}$, and $e_{j}$, denote exogenous variables or vectors of variables. For instance, in the birth probability equation (1), $z_{i}$ stands for such determinants of the optimal number of children and the spacing of births as family income, mother's education, and marital status. In the same equation $c_{j}$ is the cost of contraception, which is directly related to money price and indirectly related to availability and to contraceptive efficiency or knowledge. This cost also has a psychic component due to joint production (Grossman 1971; Michae) 1973; Pollack and Wachter 1975): an increase in contraceptive use lowers the 
probability of becoming pregnant but may also reduce the gratification yielded by sexual intercourse. The variable $a_{i}$ gives the direct, indirect, and psychic costs of obtaining an abortion. The latter cost component should be higher for Catholics than for non-Catholics. The variable $e_{i}$ measures the health endowment of the fetus.

Examples of members of the $x_{i}$ vector in the birthweight production function (2) and of the $y_{j}$ vector in the prenatal care demand function (3) are given in Section II. The roles of the $u_{j i}(j=1,2,3)$, which are linear functions of $c_{j}, a_{j}$, and $e_{j}$, are discussed below. In addition to prenatal care, the birthweight production function contains another endogenous input $\left(q_{i}\right)$, which reflects such healthy behaviors as proper diet, appropriate exercise, and the avoidance of stress. The model includes an unspecified demand function for healthy behaviors that has the same arguments as the demand function for prenatal medical care. Finally, each of the three equations contains an unspecified random disturbance term.

A reduction in the price of contraception is expected to raise the probability of giving birth $\left(\alpha_{2}<0\right)$, while an increase in the price of abortion is expected to raise this probability $\left(\alpha_{3}>0\right)$. The basic force that generates these predictions is an implicit equation for the probability of becoming pregnant. Under the plausible assumption that contraception and abortion are alternative methods of birth control, a rise in the price of contraception or a decline in the price of abortion raises this probability. As these propositions imply, pregnancies to women with low costs of averting them (low contraceptive costs) may be termed "wanted" pregnancies. It also follows that a fall in the cost of contraception or 
abortion raises the quantity of prenatal care $\left(\gamma_{2}<0, \gamma_{3}<0\right)$ and raises the level of the healthy behavior input. The force at work here is that a reduction in the cost of averting a pregnancy or a birth lowers the optimal number of children and raises the optimal amount of resources allocated to each birth (Becker and Lewis 1973; Willis 1973). This is another sense in Which a reduction in the price of averting a birth raises the level of wantedness.

It is very likely that women whose potential or actual fetuses have favorable health endowments demand a larger optimal number of children and are more likely to choose to give birth than women with unfavorable endowments $\left(\alpha_{4}>0\right)$. Moreover, the coefficients of the endowment in the demand functions for prenatal care $\left(\gamma_{4}\right)$ and the healthy behavior are negative because of a reallocation of resources away from infant health induced by a better endowment. 3

Given measures of the price of contraception, the price of abortion, the health endowment of the fetus, and the healthy behavior input, one could quantify the above effects precisely and also obtain an estimate of the coefficient of prenatal care in the birthweight production function $\left(B_{2}\right)$ that controls for the endowment and healthy behaviors. Since these variables are not observed or measured imperfectly, this is not possible. Nevertheless, it still is possible to shed considerable light on their roles in reproductive outcomes. The basic idea is to include their levels and effects in the disturbance term in each equation $\left(u_{j i}\right)$ and then obtain estimates of the covariances between disturbance terms across equations. ${ }^{4}$

To be specific, assume that $u_{j i}(j=1,2,3)$ has a zero mean, and denote 
the three pairwise covariances between the disturbance terms as $\sigma_{12}, \sigma_{13}$, and $\sigma_{23}$. Then

$$
\begin{aligned}
& \sigma_{12}=\alpha_{4} \beta_{4} \sigma_{\mathrm{e}}^{2}+\alpha_{2} \beta_{3} \sigma_{q c}+\alpha_{3} \beta_{3} \sigma_{q a} \\
& \sigma_{13}=\alpha_{4} \gamma_{4} \sigma_{\mathrm{e}}^{2}+\alpha_{2} \gamma_{2} \sigma_{\mathrm{c}}^{2}+\alpha_{3} \gamma_{3} \sigma_{\mathrm{a}}^{2} \\
& \sigma_{23}=\beta_{4} \gamma_{4} \sigma_{\mathrm{e}}^{2}+\beta_{3} \gamma_{2} \sigma_{q c}+\beta_{3} \gamma_{3} \sigma_{q a}
\end{aligned}
$$

where $\sigma_{j}^{2}(j=e, c, a)$ is the variance of variable $j$ and $\sigma_{q j}(j=c, a)$ is the covariance between $q$ and $j$. It is assumed that $e, c$, and a are mutually uncorrelated and that $q$ does not depend on $e$. (The conclusions reached are not sensitive to the lack of these relationships.) Recall that $\alpha_{3}$ and $\alpha_{4}$ are positive, while $\gamma_{2}, \gamma_{3}, \gamma_{4}, \sigma_{q c}$, and $\sigma_{q a}$ are negative. Moreover, $\beta_{3}$ and $\hat{\beta}_{4}$ are positive since an increase in the healthy behavior input or an increase in the health endowment of the fetus raises birthweight.

The sign patterns of the covariances identify whether the health endowment of the fetus, the cost of contraception, or the cost of abortion is the dominant unmeasured determinant of reproductive outcomes. For instance, suppose that the prices of abortion and contraception do not vary $\left(\sigma_{c}^{2}=\sigma_{a}^{2}=\sigma_{q c}=\sigma_{q a}=0\right)$. Then $\sigma_{12}$ is positive, while $\sigma_{13}$ and $\sigma_{23}$ are negative. That is, an increase in the health endowment raises the probability of giving birth and birthweight ( $u_{1 i}$ and $u_{2 i}$ increase), while it lowers the quantity of prenatal care demanded ( $u_{3} i$ declines). Now suppose that there is no variation in the price of abortion or in the health endowment. Then each covariance is positive. A reduction in the cost of contraception makes a birth more likely ( $u_{1 i}$ rises), causes the healthy behavior input and therefore birthweight to expand ( $u_{2} i$ rises), and causes 
the quantity of prenatal care to grow (u3i rises). Finally, if the price of abortion alone varies, $\sigma_{12}$ and $\sigma_{13}$ are negative, while $\sigma_{23}$ is positive. The health endowment model (no variation in $c$ or a) is the one emphasized by Rosenzweig and Schultz (1982, 1983a, 1983b, forthcoming a, forthcoming b) and by us in our previous research (Corman, Joyce, and Grossman 1987; Joyce 1987). It may be termed a model with adverse selection in input use because women who demand relatively large amounts of prenatal care have poor endowments. It also is a model with favorable selection in pregnancy resolution because women with relatively good endowments are more likely to give birth. The cost of contraception model (no variation in a or e) and the cost of abortion model (no variation in $c$ or e) reflect favorable selection in input use because prenatal care and healthy behaviors are positively related. The cost of contraception model is characterized by favorable selection in pregnancy resolution because women with larger optimal values of $m$ and $q$ are more likely to give birth. The reverse holds in the cost of abortion model. 5 A unique sign pattern emerges in each model, which permits one to identify the relevant one. Moreover, identification is based solely on the signs of $\sigma_{12}$ and $\sigma_{13}$, which is important because the procedure described below yields direct estimates of these two parameters.

When all three determinants vary, the sign of a given covariance is ambiguous. But their sign patterns still identify the dominant factor. ${ }^{6}$ To summarize, the estimation of the model specified here and the pairwise covariances between its disturbance terms shed light on the qualitative and quantitative importance of hard-to-measure determinants of birth outcomes. 
To be sure, some caution should be exercised in giving names to unmeasured variables. For example, the predictions made by the cost of contraception model are identical to those in a model in which women who make relatively large investments in their children are more likely to give birth for whatever reason. Indeed, the concept of "wantedness," which is emphasized by demographers and sociologists, is placed in an economic context and given an economic interpretation, by the cost of contraception mode 1 .

Moreover, other economic models can generate the same predictions as a sociological model of wantedness. For example, suppose that the price of the healthy behavior input $\left(q_{j}\right)$ varies among women. Even if the money. price of this input is the same for everyone, the time price may differ as a function of wage rates and the inconvenience costs of meal preparation and exercise. The ability of pregnant women to avoid stressful situations may depend on the nature of their jobs and family circumstances. Differences in the knowledge or perception of the health benefits of this input also generate differences in its "shadow price." The same effect can be attributed to joint production since the healthy behavior input may be a direct source of utility (or disutility) as well as an input into infant health. Hence the shadow price of $q$ as an infant health input depends in part on the monetary value of its direct marginal utility or disutility, which may vary among women. ${ }^{7}$

Let us introduce the shadow price (p) of the healthy behavior input as an additional unobservable in the birth probability equation (1) and the prenatal care demand function (3). Clearly, a reduction in $p$ raises the 
quantity of the healthy behavior input demanded. In addition, assume that it raises the birth probability, either because the optimal number of children as well as their optimal health rises or because the probability of becoming pregnant falls. ${ }^{8}$ Finally, note that the sign of $p$ in the demand function for prenatal care is ambiguous. It is negative if $m$ and $q$ are complements and positive if they are substitutes.

Under these conditions, the price of healthy behavior model (no variation in a, c, and e) makes the same predictions as the cost of contraception model if $m$ and $q$ are complements and makes the same predictions as the health endowment model if $m$ and $q$ are substitutes. We do not emphasize this model because the equation that generates selection pertains to the probability of giving birth. The cost of contraception and abortion and the health endowment of the fetus are more proximate determinants of this probability than the cost of engaging in healthy behaviors. But it should be kept in mind that our results are open to more than one interpretation. The empirical relevance of the cost of contraception model is highlighted by recent research by Forrest (1988), Forrest and Fordyce (1988), and Jones et al. (1988). These studies show that nonuse of effective contraceptive methods by women aged 15 through 44 is a point of concern in the United States. Moreover, contraceptive use is much lower and the abortion rate is much higher in the U.S. than in Canada and most Western European countries. These findings are attributed to the wider availabilty of contraceptive services and to the higher level of information concerning these services in the countries to which the U.S. Was compared. ${ }^{9}$ It is plausible that the forces that generate a larger mean shadow price of 
contraception in the U.S. also generate substantial differences in this price among U.S. residents.

Note that it is somewhat of an oversimplification to view induced abortion as a substitute for conventional contraceptive methods. In part this is the case, but abortion also is a remedy for contraceptive failure. It gives parents the option virtually to eliminate uncertainties associated with the number and spacing of births at a positive price. An analysis of the determinants of this decision is beyond the scope of this paper. But persons who find it less difficult (less costly) to correct their mistakes should be more likely to resort to an abortion in the event of a contraceptive failure. To be specific, given the considerable amount of evidence that education raises productive and allocative efficiency in the market and in the household (Welch 1970; Grossman 1972; Michael 1972; Rosenzweig and Schultz 1982a, 1983; Edwards and Grossman 1983; Wozniak 1987), the more educated may have higher abortion propensities even if they have lower costs of contraception.

To estimate the three equation model of birth outcomes, we employ procedures developed by Heckman (1979). The estimation method not only yields the covariances $\left(\sigma_{12}\right.$ and $\left.\sigma_{13}\right)$ but also recognizes that the coefficients of the birthweight production function are biased if the censored nature of the birth sample is ignored. Thus, it provides an estimate of the prenatal care coefficient $\left(\beta_{2}\right)$ that potentially controls both for adverse selection and for favorable selection in input use. This coefficient is biased downward by adverse selection and biased upward by favorable selection in computations that ignore these factors. 
Equations (1), (2), and (3) pertain to all pregnant women, but the last two are observed only for women who give birth. These are women for whom $\pi_{i} \geqslant 0$ or $u_{1} \geqslant-a_{1} z_{i}$. In such a sample, the expected value of birthweight or prenatal care is

$$
\begin{aligned}
& E\left(b_{i} \mid x_{i}, m_{i}, \pi_{i} \geqslant 0\right)=\beta_{1} x_{i}+\beta_{2} m_{i}+E\left(u_{2} \mid u_{1 i} \geqslant-a_{1} z_{i}\right) \\
& E\left(m_{i} \mid y_{i}, \pi_{i} \geqslant 0\right)=\gamma_{1} y_{i}+E\left(u_{3} \mid u_{1 i} \geqslant-a_{1} z_{i}\right) .
\end{aligned}
$$

As emphasized by Heckman, if $u_{1 i}$ and $u_{2 i}$ are correlated, the conditional mean of $\mathrm{u}_{2} i$ in equation (7) is not zero, and the regressors in the equation are correlated with the disturbance term. Hence, ordinary least squares estimates of its coefficients are biased. Exactly the same comments apply to equation (8). As we have already seen, there are good reasons to expect $\sigma_{12}$ and $\sigma_{13}$ to be nonzero.

Heckman has shown that unbiased estimates of equations (7) and (8) can be obtained under the assumption that the joint distributions of $u_{1} i, u_{2} i$ and $u_{1 i}, u_{3} i$ are bivariate normal densities. His procedure is to fit the birth probability equation (1) as a probit function and to compute the inverse of Mill's ratio $\left(\lambda_{i}\right)$ for each woman who gives birth:

$$
\lambda_{i}=f\left(Q_{j}\right) / F\left(Q_{j}\right)
$$

Here $Q_{i}=a_{1} z_{i} / \sigma_{1}$ and $f$ and $F$ are, respectively, the density and distribution functions for a standard normal variable. The inverse of Mill's ratio is then inserted as a regressor in equations (7) and (B) which, after adding disturbance terms with zero means $\left(v_{2} i\right.$ and $\left.v_{3}\right)$, become 


$$
\begin{aligned}
& b_{1}=\beta_{1} x_{i}+\beta_{2} m_{i}+\left(\sigma_{12} / \sigma_{1}\right) \lambda_{i}+v_{2 i} \\
& m_{i}=\gamma_{1} y_{i}+\left(\sigma_{13} / \sigma_{1}\right) \lambda_{i}+v_{3 i} .
\end{aligned}
$$

Note that the coefficients of $\lambda_{i}$ in $(10)$ and (11) estimate $\sigma_{12}$ and $\sigma_{13}$, respectively, up to a positive scale factor $\left(1 / \sigma_{1}\right) .10$

One conceptual issue that arises in the context of the estimation of the model pertains to the potential endogeneity of prenatal care in the birthweight production function. It is clear that $m_{i}$ and the disturbance term $\left(u_{2 j}\right)$ in the birthweight production function (2) are correlated if $u_{2 i}$ is correlated with the disturbance term $\left(u_{3 i}\right)$ in the demand function for prenatal care (3). From equation (6), $\sigma_{23}$ is nonzero unless $-\beta_{4} \gamma_{4} \sigma_{e}^{2}=\beta_{3} \gamma_{2} \sigma_{\mathrm{qc}}+\beta_{3} \gamma_{3} \sigma_{\mathrm{qa}}$. Although the disturbance terms in (2) and (3) undoubtedly are correlated, the disturbance terms in (10) and (11) are less likely to be correlated because both equations include the inverse of Mill's ratio $\left(\lambda_{i}\right)$ as a regressor. Differences in $\lambda_{i}$ among women who give birth reflect differences in the health endownent of the fetus and the costs of contraception and abortion. Since these factors generate the correlation between disturbance terms, the biases that they introduce are reduced when $\lambda_{1}$ is employed in the equation.

More formally, weighted (to correct for heteroskedacticity) ordinary least squares estimation of the birthweight production function is appropriate when a single factor generates the three covariances among the disturbance terms. For example, suppose that only the health endowment varies. Then each of the three pairwise correlation coefficients $\left(\rho_{i j}\right)$ equals one in absolute value, and the coefficient of $\lambda_{j}$ in the estimated 
birthweight equation $\left(\beta_{4} \gamma_{4} \sigma_{e}\right)$ differs from the coefficient of the health endowment $(e)$ in the structural birthweight equation $\left(\beta_{4}\right)$ only by a positive scale factor $\left(\alpha_{4} \sigma_{e}\right)$. Now suppose that cost of contraception model fully described the data. Then $\rho_{12}=\rho_{23}=\sigma_{q c} / \sigma_{c}$ and $\rho_{13}=1$. Once again, the coefficient of $\lambda_{i}$ in the birthweight production function $\left(\beta_{3} \alpha_{2} \sigma_{q c} / \sigma_{c}\right)$ differs from the coefficient of the healthy behavior input $(q)$ in the structural equation $\left(\beta_{3}\right)$ only by a positive scale factor $\left(\alpha_{2} \sigma_{q c} / \sigma_{c}\right)$. When more than one factor varies, two-stage least squares estimation of the production function with prenatal care treated as an endogenous variable may be appropriate. We examine this proposition by using the two-stage least squares probit method for simultaneous equations models with selectivity developed by Lee, Maddala, and Trost (1980) and the Wu-Hausman endogeneity test (Wu 1973; Hausman 1978).

\section{Data and Estimation}

Data on births and abortions are from New York City vital statistics in 1984. In that year there were approximately 105,000 singleton live births and 89,000 induced abortion to New York City residents. Our analys is is based on randomly chosen subsamples of the combined population of births and induced abortions. ${ }^{12}$ We examined 11,591 pregnancies to white, non-Hispanic women twenty years and older and 11,016 pregnancies to black, non-Hispanic women of the same age. ${ }^{13}$ We excluded adolescents in order to minimize problems of endogeneity. This issue is discussed in greater detail below.

Our analysis is made possible because many of the parental charac- 
teristics reported on the birth certificates are also reported on the induced termination records. Thus, by concatenating the data sets we were able to specify an equation predicting the probability of giving birth, given a woman was pregnant. A description of the variables is provided in Table 1. The means and proportions within each subsample are presented in Table 2 .

Data from the abortion and birth certificates were augmented with 1980 census data which had been aggregated from the census tract to the health area leve1. The health area is the smallest geographical area identified on the birth and abortion certificates. New York City is divided into 352 health areas. The average health area contains between 15,000 and 25,000 residents. The census data enabled us to calculate the percentage of persons below the poverty level in each health area by race.

The vital statistics were also augmented with variables that measure the availability of various reproductive health services. Combining data from the Alan Guttmacher Institute and the New York City Department of Health. we knew the number of family planning clinics, abortion providers, and prenatal clinics by health area in 1983. These availability measures were divided by the number of women 15 to 44 in a health area in 1980 . The denominators were from the 1980 census. A fourth availability measure was a dichotomous variable that equaled one if the women lived in a health district in which was located a health center operated by the Federal Supplemental Food Program for Women, Infants, and Children (WIC). 14 WIC had thirteen locations in New York City in 1983 where women could enroll and receive food coupons. Nine of these centers also housed maternal and 
Table 1

Description of Variables

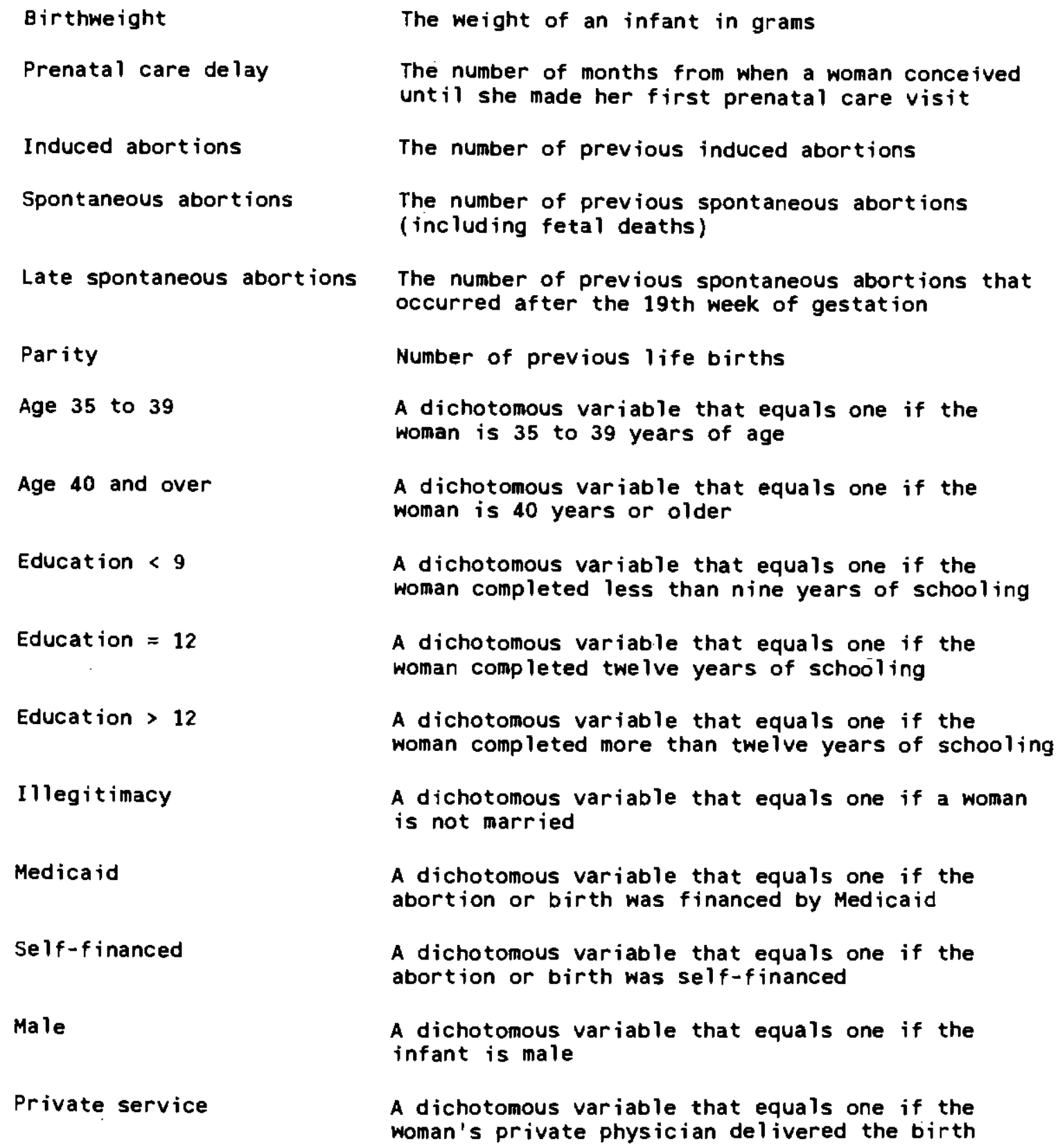


Table 1 (continued)

Narcotics

Tobacco

Alcohol

Family planning clinic

Abortion providers

Prenatal care clinics

WIC center

Poverty

Lambda
A dichotomous variable that equals one if the pregnancy was complicated by narcotics

A dichotomous variable that equals one if the pregnancy was complicated by smoking

A dichotomous variable that equals one if the pregnancy was complicated by alcohol

The number of family planning clinics per 10,000 women 15 to 44 in a health area

The number of abortion providers per 10,000 women 15 to 44 in a health area

The number of prenatal care clinics per 10,000 women 15 to 44 in a health area

A dichotomous variable that equals one if the woman resided in a health area district that contained an office for the Supplemental Nutrition Program for Women, Infants and Children

The race- and ethnic-specific percentage of people below the poverty level in 1980 in a health area; measure for whites includes both white Hispanics and white non-Hispanics; similar comment applies to measure for blacks

The inverse Mill's ratio which is a monotonically decreasing function of the probability of giving birth given that a woman is pregnant 
Table 2

Means by Pregnancy Outcome For White and Black Women Twenty Years and Older

\begin{tabular}{|c|c|c|c|c|}
\hline & \multicolumn{2}{|c|}{ Whites } & \multicolumn{2}{|c|}{ Blacks } \\
\hline & Births & Abortions & Births & Abortions \\
\hline $\begin{array}{l}\text { Birthwe ight } \\
\text { Illegitimacy }\end{array}$ & $\begin{array}{r}3,381 \\
.08\end{array}$ & .69 & $\begin{array}{r}3.173 \\
.55\end{array}$ & .76 \\
\hline Education $<9$ & .02 & .02 & .04 & .01 \\
\hline Education $=12$ & .44 & .43 & .45 & .57 \\
\hline $\begin{array}{l}\text { Education > } 12 \\
\text { Male }\end{array}$ & $\begin{array}{l}.49 \\
.50\end{array}$ &.- .48 & $\begin{array}{l}.31 \\
.51\end{array}$ & $\ldots .28$ \\
\hline Age 35 to 39 & .12 & .10 & .08 & .08 \\
\hline Age 40 and over & .02 & .02 & .02 & .02 \\
\hline Medicaid & .08 & .14 & .46 & .46 \\
\hline Self-financed & .10 & .66 & .10 & .32 \\
\hline Private service & .86 & .69 & .34 & .62 \\
\hline Prenatal care delay & 3.26 & --- & 4.88 & --- \\
\hline $\begin{array}{l}\text { Parity } \\
\text { Total induced abortions }\end{array}$ & $\begin{array}{l}.86 \\
.22\end{array}$ & $\begin{array}{r}.76 \\
1.04\end{array}$ & $\begin{array}{r}1.26 \\
.50\end{array}$ & $\begin{array}{l}1.52 \\
1.30\end{array}$ \\
\hline Late induced abortions & .01 & -- & .01 & -- \\
\hline Total spontaneous abortions & .17 & .12 & .22 & .17 \\
\hline Late spontaneous abortions & .01 & -- & .02 & -- \\
\hline Tobacco & .02 & --- & .06 & $-\cdots$ \\
\hline Alcohol & .01 & --- & .01 & --- \\
\hline Narcotics & .004 & --- & .01 & --- \\
\hline Abortion clinics & .63 & .73 & .60 & .54 \\
\hline Family planning clinics & .74 & .94 & 1.41 & 1.36 \\
\hline Prenatal care clinics & .67 & .70 & 1.04 & .96 \\
\hline $\begin{array}{l}\text { WIC centers } \\
\text { Poverty }\end{array}$ & $\begin{array}{r}.30 \\
12.18\end{array}$ & $\begin{array}{r}.29 \\
13.60\end{array}$ & $\begin{array}{r}.57 \\
29.38\end{array}$ & $\begin{array}{r}.54 \\
29.76\end{array}$ \\
\hline Lambda & .34 & -.59 & .74 & -.60 \\
\hline Observations & 7,362 & 4,229 & 4,924 & 6,092 \\
\hline
\end{tabular}


infant care (M and I) projects. They provide prenatal and obstetrical care to poor women under the 1963 amendment to Title $V$ of the Social Security Act.

The weight of a child at birth is our indicator of infant health [(equation (2)]. The literature linking birthweight to infant mortality and childhood morbidity is voluminous (Institute of Medicine 1985). Prenatal care is measured by the number of months a woman delays before seeking medical care for her pregnancy (equation 3 ). Women who received no care are assumed to have delayed 10 months. This prenatal care measure should be negatively related to birthweight. The birth probability equation has a dichotomous dependent variable: one if the women gives birth, zero if she aborts [(equation (1)].

The specification of the birthweight production function is based on the structural relationship between medical and biological inputs and the birth outcome. Thus, in addition to prenatal care, we include the newborn's sex, dichotomous variables for older women and marital status, the number of previous live births as well as the number of previous late spontaneous abortions. The latter two inputs may control for, in part, a woman's reproductive capability. To measure the quality of care we include an indication of whether the child was delivered by the patient's private physician or whether the delivery was performed by a general service physician. Following Grossman (1972), mother's education is used to control for efficiency in household production. Finally, we employ three dichotomous variables that indicate whether the pregnancy was complicated by alcohol. drugs, or tobacco. 
We treat the prenatal care demand equation (equation 3 ) and birth probabflity equation as reduced forms. In addition to the mother's characteristics such as age, marital status, and obstetric history, we included the method of finance as well as the areal measures of reproductive health services and the race-specific poverty rate. The method of finance has three categories: Medicaid, other third party (private health insurance or health maintenance organization), or self-pay. 15

With respect to prenatal care, we expect women on Medicaid and women who paid for the birth themselves to delay the initiation of prenatal care longer than women whose care is financed by private health insurance. Women applying for Medicaid for the first time may experience delays in processing their applications. Moreover, all Medicaid recipients may face greater search costs since many providers do not accept Medicaid due to the level of reimbursement. In the birth probability equation, however, it is unclear a priori whether Medicaid recipients are more likely to abort than non-Medicaid recipients. New York State finances abortions for Medicaid eligible women, and thus the out-of-pocket costs are zero. Yet, Medicaid status clearly measures poverty. If the opportunity costs of giving birth are lower for poor than nonpoor women, then Medicaid status could be positively related to the probability of giving birth.

As discussed in Section I, we apply Heckman's two-step procedure to correct for biases due to self-selection. Following Lee, Trost and Maddala (1980) we also estimate a model in which prenatal care is treated as an endogenous input in the birthweight equation. Both models require that we impose restrictions in order to achieve identification. As mentioned 
above, the birthweight equation excludes measures of income and availability. At the same time it includes the sex of the child and whether the birth was complicated by alcohol, narcotics, or tobacco, and whether the birth was delivered by a private physician. Thus, the birthweight equation easily meets the rank and order conditions for indentification.

Identification of the prenatal care demand function is more problematic. Identification can be achieved via the nonlinear relationship between the inverse of Mill's ratio $(\lambda)$ and the regressors in the birth probability equation. In other words, even if the vector $z_{i}$ in equation (1) and the vector $y_{i}$ in equation (3) contain the same set of variables, the equations are still identified. Nevertheless, the model is on firmer grounds if there are unique determinants of each equation.

We assume that the availability of family planning clinics, the availability of abortion providers, and the number of previous induced abortions have no impact on the demand for prenatal care. This is most defensible in a model in which variations in the health endowment are small, so that differences in the monetary and psychic costs of contraception and abortion are fully captured by variations in $\lambda$. Moreover, unlike spontaneous abortions, there is little evidence that links induced abortions to subsequent reproductive difficulties (Hogue, Cates, and Tietze 1982). We include parity in the prenatal care demand equation but exclude it from the birth probability equation because the left-hand side of the latter equation is mechanically related to parity. ${ }^{16}$ We include parity in the prenatal care demand function because it proxies experience with pregnancy and birth. In addition, parity and the number of late spontaneous abortions may control, 
in part, for a woman's health endowment. Finally, the availability of prenatal care clinics and WIC centers are obvious determinants of the receipt of early prenatal care but much less closely related to optimal family size and the decision to give birth. 17

Although the birth probability function is termed a reduced form equation, certain regressors in it are potentially endogenous. Among teenagers, for instance, education may determine the probability of aborting, but the years of schooling completed is clearly related to the time spent pregnant (Hofferth 1987). A similar issue occurs between Medicaid status and pregnancy resolution. Among unmarried, nulliparous adolescents, giving birth is a precondition for receiving continued support from Medicaid and additional support from welfare. Marital status is a third example. Between 1980 and 1981,28 percent of all white first births to adolescents were conceived premaritally, but born inside of marriage (O'Connell and Rogers 1984). In short, the decision to give birth, especially among adolescents, may be determined simultaneously with the decision to complete school, apply for Medicaid, or get married (Leibowitz, Eisen, and Chow 1986; Joyce 1988). Therefore, to minimize these problems we estimate the model for women twenty years of age or more since the endogeneity of marital status. Medicaid, and education should be less relevant for these women.

We treat prenatal medical care as the only endogenous variable in the birthweight production function, yet other variables in this equation could be viewed in a similar manner. These include mother's age, parity, and cigarette smoking, all of which are treated as endogenous by Rosenzweig and 
Schultz (1982, 1983b, forthcoming a, forthcoming.b) in the estimation of birthweight production functions in the 1967-69 and 1980 U.S. National Natality followback Surveys. We examine the endogeneity of prenatal care alone in the production function because we have a well-specified equation for the demand for this input. Moreover, both the birthweight production function and the prenatal care demand function must be estimated to ascertain whether the cost of contraception, the cost of abortion, or the health endowment of the fetus is the dominant unmeasured determinant of reproductive outcomes. The estimation of other equations is not essential in accomplishing this goal. Since prenatal care is the dependent variable in the demand function, it is logical to consider its endogeneity in the production function.

We do not deny the validity of Rosenzweig and Schultz's methodology and the value of their contribution. We wish to emphasize, however, that our objective is different from theirs. We incorporate the choice-based nature of micro vital records into the estimation of birthweight production functions, while they focus solely on live births. In contrast, their aim is to treat a variety of variables as endogenous. In addition to the different objectives of the studies, we do not endogenize variables other than prenatal care because Rosenzweig and Schultz use national samples. Thus, many more instrumental variables are available to them. 18 Moreover, the twostage least squares estimates on which they focus are not obtained at zero cost. One of their main instrumental variables is mother's schooling which may be determined simultaneously with family size, particularly since they do not exclude teenagers. In addition, Rosenzweig and Schultz onit 
mother's schooling from the birthweight production function. Although they present statistical evidence in support of this exclusion (Rosenzweig and Schultz 1981), it is not consistent with the theoretical and empirical literature on the productive efficiency of education in nonmarket production that we have cited.

Finally, we choose a linear functional form because the true relatronship between birthweight and infant or childhood health is not known. The linear form has the virtue of simplicity. The use of a linear functional form rules out an investigation of the optimal input mix (the combination of inputs that minimize the cost of producing a given level of infant health), but this is not the focus of our empirical research. Moreover, we include only one measured endogenous input.

\section{Results}

Empirical estimates of the birth probability equation and prenatal care demand equations are presented in Table 3. The birth probability equation is estimated by maximum likelihood probit. Two estimates of the prenatal care demand equation are shown. The first is estimated by ordinary least squares (OLS) without correcting for selection. The second employs the inverse of Mili's ratio as a regressor and adjusts the standard errors as suggested by Heckman (1979). Table 4 presents three estimates of the birthweight production function. The first equation is obtained by OLS with no attempt to correct for selection or endogeneity. The second specification corrects for selection but treats prenatal care as exogenous. The third uses the two-stage least squares (TSLS) procedure outlined by Lee, Maddala, Trost 
Table 3

Birth Probability and Prenatal Care (Months of Oelay) Denand for White and Black Women Twenty Years and 01 der

\begin{tabular}{|c|c|c|c|c|c|c|}
\hline & \multicolumn{3}{|c|}{ Whites } & \multicolumn{3}{|c|}{81 acks } \\
\hline & $\begin{array}{l}\text { Probit } \\
\text { (1) }\end{array}$ & $\begin{array}{l}\text { Prenatal } \\
\text { Care } \\
\text { (2) }\end{array}$ & $\begin{array}{l}\text { Prenata } 1 \\
\text { Care* } \\
\text { (3) }\end{array}$ & $\begin{array}{l}\text { Probit } \\
\text { (4) }\end{array}$ & $\begin{array}{l}\text { Prenata } 1 \\
\text { Core } \\
\text { (5) }\end{array}$ & $\begin{array}{l}\text { Prenata } \\
\text { Care* } \\
\text { (6) }\end{array}$ \\
\hline Intercept & $\begin{array}{l}1.524 \\
(21.73)\end{array}$ & $\begin{array}{c}3.311 \\
(33.34)\end{array}$ & $\begin{array}{c}3.304 \\
(32.93)\end{array}$ & $\begin{array}{c}.836 \\
(15.79)\end{array}$ & $\begin{array}{c}4.093 \\
(28.06)\end{array}$ & $\begin{array}{r}4.197 \\
(27.18\end{array}$ \\
\hline Abortion providers & $\begin{array}{l}-.026 \\
(-2.21)\end{array}$ & & & $\begin{array}{c}.026 \\
(2.06)\end{array}$ & & \\
\hline Fanily planning clinics & $\begin{array}{l}-.006 \\
(-.59)\end{array}$ & & & $\begin{array}{l}.005 \\
(.71)\end{array}$ & & \\
\hline Prenatal care clinics & & $\begin{array}{l}-.013 \\
(-.87)\end{array}$ & $\begin{array}{l}-.014 \\
(-.90)\end{array}$ & --- & $\begin{array}{l}-.031 \\
(-1.41)\end{array}$ & $\begin{array}{l}-.034 \\
(-1.55\end{array}$ \\
\hline HIC centers & & $\begin{array}{l}.006 \\
(-.14)\end{array}$ & $\begin{array}{l}-.006 \\
(-.14)\end{array}$ & $\begin{array}{l}--- \\
---\end{array}$ & $\begin{array}{l}-.35 d \\
(-4.95)\end{array}$ & $\begin{array}{r}-.355 \\
(-4.97\end{array}$ \\
\hline Poverty & $\begin{array}{l}-.004 \\
(-.235)\end{array}$ & $\begin{array}{c}.014 \\
(5.53)\end{array}$ & $\begin{array}{c}.014 \\
(5.49)\end{array}$ & $\begin{array}{l}.0004 \\
(.34)\end{array}$ & $\begin{array}{c}.019 \\
(5.99)\end{array}$ & $\begin{array}{r}.019 \\
(6.02\end{array}$ \\
\hline Medicaid & $\begin{array}{c}.351 \\
(6.84)\end{array}$ & $\begin{array}{c}1.238 \\
(14.44)\end{array}$ & $\begin{array}{l}1.244 \\
(14.34)\end{array}$ & $\begin{array}{l}.163 \\
(5.60)\end{array}$ & $\begin{array}{c}.909 \\
(10.38)\end{array}$ & $\begin{array}{r}.862 \\
19.98\end{array}$ \\
\hline Self-pay & & $\begin{array}{c}.477 \\
(7.24)\end{array}$ & $\begin{array}{c}.476 \\
(7.24)\end{array}$ & $\begin{array}{l}--- \\
---\end{array}$ & $\begin{array}{l}1.169 \\
(9.48)\end{array}$ & $\begin{array}{l}1.160 \\
19.42\end{array}$ \\
\hline $\begin{array}{l}\text { Total spontaneous abortions } \\
\text { Total induced abortions }\end{array}$ & $\begin{array}{l}.091 \\
(2.95) \\
-.560 \\
(-31.43)\end{array}$ & & & $\begin{array}{c}.132 \\
(5.51) \\
-.447 \\
(-33.94)\end{array}$ & -- & \\
\hline Schooling < 9 & $\begin{array}{l}-.548 \\
(-4.77)\end{array}$ & $\begin{array}{c}.340 \\
(2.01)\end{array}$ & $\begin{array}{c}.330 \\
(1.94)\end{array}$ & $\begin{array}{c}.461 \\
(4.92)\end{array}$ & $\begin{array}{l}-.140 \\
(-.72)\end{array}$ & $\begin{array}{r}-.193 \\
1-.96\end{array}$ \\
\hline Schooling $=12$ & $\begin{array}{l}-.262 \\
(-3.97)\end{array}$ & $\begin{array}{l}-.490 \\
(-5.10)\end{array}$ & $\begin{array}{l}-.494 \\
(-5.13)\end{array}$ & $\begin{array}{c}-.420 \\
(-11.35)\end{array}$ & $\begin{array}{l}-.264 \\
(-2.69)\end{array}$ & $\begin{array}{r}-.192 \\
(-1.65\end{array}$ \\
\hline Schooling > 12 & $\begin{array}{l}-.174 \\
(-2.60)\end{array}$ & $\begin{array}{l}-.594 \\
(-6.06)\end{array}$ & $\begin{array}{l}-.598 \\
(-6.09)\end{array}$ & $\begin{array}{c}-.225 \\
(-5.45)\end{array}$ & $\begin{array}{l}-.580 \\
(-5.25)\end{array}$ & $\begin{array}{r}-.533 \\
(-4.74\end{array}$ \\
\hline Age 35 to 39 & $\begin{array}{l}-.049 \\
(-1.05)\end{array}$ & $\begin{array}{l}-.083 \\
(-1.33)\end{array}$ & $\begin{array}{l}-.085 \\
(-1.36)\end{array}$ & $\begin{array}{l}-.090 \\
(-1.87)\end{array}$ & $\begin{array}{l}-.301 \\
(-2.25)\end{array}$ & $\begin{array}{l}-.297 \\
(-2.22\end{array}$ \\
\hline Age 40 to 44 & $\begin{array}{l}-.596 \\
(-6.74)\end{array}$ & $\begin{array}{l}-.234 \\
(-1.57)\end{array}$ & $\begin{array}{l}-.247 \\
(-1.63)\end{array}$ & $\begin{array}{l}-.404 \\
(-4.32)\end{array}$ & $\begin{array}{l}-.272 \\
(-.98)\end{array}$ & $\begin{array}{r}-.225 \\
(-.81\end{array}$ \\
\hline Late spontaneous abortions & & $\begin{array}{l}-.057 \\
(-.25)\end{array}$ & $\begin{array}{l}-.057 \\
(-.25)\end{array}$ & & $\begin{array}{l}-.060 \\
(-.30)\end{array}$ & $\begin{array}{r}-.074 \\
1-.37\end{array}$ \\
\hline Illegitimate & $\begin{array}{c}-1.915 \\
(-57.27)\end{array}$ & $(11.513)$ & $\begin{array}{c}.854 \\
(5.80)\end{array}$ & $\begin{array}{c}-.654 \\
(-22.55)\end{array}$ & $\begin{array}{c}.098 \\
(1.23)\end{array}$ & $(2.18$ \\
\hline Parity & & $\begin{array}{c}.096 \\
(5.69)\end{array}$ & $\begin{array}{l}.096 \\
(5.67)\end{array}$ & & $\begin{array}{c}.174 \\
(6.51)\end{array}$ & $\begin{array}{c}.181 \\
(5.71\end{array}$ \\
\hline Lanbda & & & $\begin{array}{l}.050 \\
(.47)\end{array}$ & & & $\begin{array}{l}-.278 \\
(-2.03)\end{array}$ \\
\hline F-statistic & & 85.04 & 78.98 & & 38.50 & 36.07 \\
\hline Chi-squared & 6130 & & & 2238.3 & & \\
\hline $\begin{array}{l}\text { R-squared } \\
\text { Observations }\end{array}$ & 11.589 & $\begin{array}{l}.131 \\
7361\end{array}$ & $\begin{array}{r}.131 \\
7361\end{array}$ & 11016 & $\begin{array}{r}.092 \\
4924\end{array}$ & .093 \\
\hline
\end{tabular}

\footnotetext{
*orrected for selection.
} 


\section{$-28-$ \\ Table 4}

Birthweight Production Functions For white and Black Women Twenty Years and older

\begin{tabular}{|c|c|c|c|c|c|c|}
\hline & \multicolumn{3}{|c|}{ Whites } & \multicolumn{3}{|c|}{ Blacks } \\
\hline & $\overline{\mathrm{OLS}}$ & OLS* & TSLS*ネ & OLS & OLS* & $\overline{T S L S * \pi}$ \\
\hline Intercept & $\begin{array}{r}3236.840 \\
(86.05)\end{array}$ & $\begin{array}{r}3231.580 \\
(05.38)\end{array}$ & $\begin{array}{r}3304.470 \\
(42.42)\end{array}$ & $\begin{array}{r}3154.790 \\
(93.39)\end{array}$ & $\begin{array}{l}3126.60 \\
(188.39)\end{array}$ & $\begin{array}{r}3253.200 \\
(31.58)\end{array}$ \\
\hline Schooling < 9 & $\begin{array}{c}142.706 \\
(2.78)\end{array}$ & $\begin{array}{r}135.660 \\
(2.63)\end{array}$ & $\begin{array}{r}142.112 \\
(2.73)\end{array}$ & $\begin{array}{c}51.477 \\
(1.10)\end{array}$ & $\begin{array}{c}67.109 \\
(1.42)\end{array}$ & $\begin{array}{l}61.977 \\
(1.27)\end{array}$ \\
\hline Schooling $=12$ & $\begin{array}{l}47.513 \\
(1.64)\end{array}$ & $\begin{array}{l}13.615 \\
(1.50)\end{array}$ & $\begin{array}{r}31.072 \\
(.99)\end{array}$ & $\begin{array}{c}60.697 \\
(2.60)\end{array}$ & $\begin{array}{r}37.820 \\
(1.52)\end{array}$ & $\begin{array}{l}28.640 \\
(1.09)\end{array}$ \\
\hline Schooling > 12 & $\begin{array}{l}71.021 \\
(2.41)\end{array}$ & $\begin{array}{l}67.472 \\
(2.28)\end{array}$ & $\begin{array}{l}50.819 \\
(1.54)\end{array}$ & $\begin{array}{r}84.098 \\
(3.16)\end{array}$ & $\begin{array}{r}68.990 \\
(2.54)\end{array}$ & $\begin{array}{l}45.821 \\
(1.48)\end{array}$ \\
\hline Age 35 to 39 & $\begin{array}{r}-32.386 \\
(-1.72) \\
14.816\end{array}$ & $\begin{array}{r}-33.760 \\
(-1.79) \\
5.282\end{array}$ & $\begin{array}{r}-36.478 \\
(-1.92) \\
-.346\end{array}$ & $\begin{array}{r}21.205 \\
(.66) \\
-61.360\end{array}$ & $\begin{array}{r}19.271 \\
(.61) \\
-76.584\end{array}$ & $\begin{array}{r}8.312 \\
(.25) \\
-85.518\end{array}$ \\
\hline Late spontaneous abortions & $\begin{array}{l}-94.597 \\
(-1.39)\end{array}$ & $\begin{array}{r}-94.864 \\
(-1.40)\end{array}$ & $\begin{array}{r}-96.308 \\
(-1.42) \\
-111\end{array}$ & $\begin{array}{l}-58.265 \\
(-1.22) \\
-66.120\end{array}$ & $\begin{array}{l}-53.575 \\
(-1.12) \\
-99.938\end{array}$ & $\begin{array}{l}-55.618 \\
(-1.13) \\
-82.897\end{array}$ \\
\hline Illegitimate & $\begin{array}{l}-98.187 \\
(-4.04)\end{array}$ & $\begin{array}{r}-139.368 \\
(-3.22)\end{array}$ & $\begin{array}{c}-111.093 \\
(-2.232) \\
28.069\end{array}$ & $\begin{array}{r}-66.120 \\
(-3.64) \\
8.324\end{array}$ & $\begin{array}{r}-99.938 \\
(-4.50) \\
6.531\end{array}$ & $\begin{array}{r}-82.897 \\
(-3.34) \\
12.306\end{array}$ \\
\hline Parity & $\begin{array}{l}25.261 \\
(5.11)\end{array}$ & $\begin{array}{l}25.215 \\
(5.09)\end{array}$ & 28.069 & $\begin{array}{r}8.324 \\
(1.30) \\
24.975\end{array}$ & $\begin{array}{l}6.531 \\
(1.01) \\
20.520\end{array}$ & $\begin{array}{l}12.306 \\
(1.61) \\
22.615\end{array}$ \\
\hline Private service & $\begin{array}{l}34.094 \\
(1.70)\end{array}$ & $\begin{array}{l}34.204 \\
(1.71)\end{array}$ & $\begin{array}{l}32.825 \\
(1.66)\end{array}$ & 24.975 & $\begin{array}{r}(1.00) \\
114.995\end{array}$ & $\begin{array}{l}(1.02) \\
114.79\end{array}$ \\
\hline Msle & $\begin{array}{l}120.366 \\
(10.10)\end{array}$ & $\begin{array}{l}120.226 \\
(10.09)\end{array}$ & $\begin{array}{l}119.652 \\
(10.02)\end{array}$ & $\begin{array}{r}114.054 \\
(6.79)\end{array}$ & $\begin{array}{r}114.995 \\
(6.86)\end{array}$ & $(6.64)$ \\
\hline Tobacco & $\begin{array}{r}-44.615 \\
(-.90)\end{array}$ & $\begin{array}{r}-44.341 \\
(-.89)\end{array}$ & $\begin{array}{r}-42.416 \\
(-.85)\end{array}$ & $\begin{array}{r}-188.901 \\
(-5.14)\end{array}$ & $\begin{array}{r}-186.753 \\
(-5.09)\end{array}$ & $\begin{array}{r}-187.156 \\
(-4.95)\end{array}$ \\
\hline Alcohol & $\begin{array}{r}248.803 \\
(3.91)\end{array}$ & $\begin{array}{r}249.147 \\
(3.94)\end{array}$ & $\begin{array}{r}253.288 \\
(3.98)\end{array}$ & $\begin{array}{r}47.816 \\
(.48)\end{array}$ & $\begin{array}{r}49.387 \\
(.50)\end{array}$ & $\begin{array}{r}55.985 \\
(.55)\end{array}$ \\
\hline Narcotics & $\begin{array}{r}-356.786 \\
(-3.86)\end{array}$ & $\begin{array}{r}-361.728 \\
(-3.91)\end{array}$ & $\begin{array}{r}-362.335 \\
(-3.91)\end{array}$ & $\begin{array}{r}-325.128 \\
(-4.52\}\end{array}$ & $\begin{array}{r}-334.900 \\
(-4.66)\end{array}$ & $\begin{array}{r}-352.625 \\
(-4.79)\end{array}$ \\
\hline Prenatal care delay & $\begin{array}{r}-4.472 \\
(-1.22)\end{array}$ & $\begin{array}{l}-4.384 \\
(-1.20)\end{array}$ & $\begin{array}{r}-23.145 \\
(-1.35)\end{array}$ & $\begin{array}{l}-12.616 \\
(-3.60)\end{array}$ & $\begin{array}{l}-12.380 \\
(-3.54)\end{array}$ & $\begin{array}{l}-37.428 \\
(-1.97)\end{array}$ \\
\hline Lambda & & $\begin{array}{l}36.149 \\
(1.15)\end{array}$ & $\begin{array}{l}33.192 \\
(1.05)\end{array}$ & & $\begin{array}{l}85.606 \\
(2.64)\end{array}$ & $\begin{array}{l}74.022 \\
(2.16)\end{array}$ \\
\hline $\begin{array}{l}F-s t a t i s t i c \\
\text { Wu-test } F * \star \star\end{array}$ & 16.29 & $\begin{array}{l}15.27 \\
2.30\end{array}$ & & 14.38 & $\begin{array}{l}13.90 \\
2.03\end{array}$ & \\
\hline R-squared & .030 & .030 & & .039 & .041 & \\
\hline Observations & 7362 & 7362 & 7362 & 4924 & 4924 & 4924 \\
\hline
\end{tabular}

* Corrected for selection.

** Prenatal care delay is endogenous.

t** The critical $F(1, \infty)$ at the 5 percent level is 3.84 . 
(1980) to correct for the endogeneity of prenatal care as well as for selectivity.

Regardless of race, legitimacy status, the number of previous induced abortions, the number of previous spontaneous abortions, and Medicaid eligibility are statistically significant predictors of the probability of giving birth. In particular, women who are not married, and women who have had at least one induced abortion prior to the current pregnancy are less likely to give birth. Women who are eligible for Medicaid and women who have involuntarily lost a previous pregnancy are more likely to give birth. As indicated in Section II, the sign of the Medicaid effect is ambiguous on a priori grounds. Therefore, the last result is notable because it duplicates the one found in a recent study of adolescents by Leibowitz, Eisen, and Chow (1986). They reported that unmarried teenagers who were eligible for Medicaid financing of an abortion or a delivery were more likely to keep their babies in a sample of California residents in the period 1972-74.

Among blacks, there appears to be a linear relationship between years of completed schooling and the likelihood of an abortion. However, among whites, the relationship is more u-shaped. White pregnant women with between nine and eleven years of schooling are the most likely to give birth. Following national aggregates, older pregnant women of both races have a greater probability of terminating the current pregnancy than women twenty to thirty-four years of age (Henshaw et al. 1985).

With regard to the areal characteristics, white women living in neighborhoods of relative poverty have a greater than average propensity to 
abort. Poverty has no impact on pregnancy resolution among blacks. The availability of abortion providers increases the probability of terminating a pregnancy for white women, but it has the opposite effect for black women.

In discussing the birthweight production functions and prenatal care demand functions, we focus on the role of sample selection bias and on the effect of prenatal care on birthweight. There is strong evidence of selectivity bias in the birthweight production function and prenatal demand equation among blacks. There is no evidence of such bias among whites. For blacks, the results suggest that the unobserved factors which raise the probability of giving birth are positively correlated with the unobserved factors that decrease delay in the initiation of prenatal care and increase birthweight. For black women the sign patterns among the residual covariances are consistent with a model that emphasizes the cost of contraceptive. In particular, black women for whom the shadow price of contraception is relatively high are more likely to experience an unintended pregnancy and more likely to carry the pregnancy to term than their counterparts who face a lower shadow price and whose pregnancies were more likely to have been planned. The latter group should consume more prenatal care (delay less) and invest in other healthy behaviors that improve birthweight.

One explanation for the racial differences with respect to selectivity bias is that the shadow price of contraception is greater for blacks than it is for whites. Further, the shadow price is apt to vary more among blacks than it does among whites. Racial differences in contraceptive use and abortion are consistent with this interpretation (Pratt et al. 1984; 
Henshaw et al. 1985; Stephen, Rindfuss, and Bean 1988).

Failure to correct for self-selection can yield biased estimates of the health technology. For example, the effect of illegitimacy rises by 50 percent in absolute value when lambda is included in the birthweight equation for blacks. Since unmarried women are more likely to abort, those who do not abort may have lower contraceptive costs. As a result, the coefficient on illegitimacy is understated if lambda is omitted. It should also be noted that the impact of post-secondary education falls and the incremental benefit of a high school diploma becomes statistically insignificant when selectivity bias is corrected.

Our results for blacks indicate that women who aborted would have given birth to lighter infants if they had selected the birth option and if they had had the same mean values of the observed variables in the birthweight equation as women who actually gave birth. One way to gauge the magnitude of the effect is to compare it to that of an observed risk factor for birth outcomes. Among blacks, complication due to smoking reduce birthweight by 187 grams or by 5.8 percent relative to a mean of 3,184 for pregnancies not complicated by smoking. 19 on the other hand, potential mean birthweight in the abortion sample falls short of birthweight in the birth sample by 118 grams due to unobserved inputs alone. 20 This amounts to a differential of 3.7 percent relative to the observed mean of 3,173 for all black women in the birth sample. Thus, the impact of unobserved healthy behaviors is almost two-thirds as large in absolute value as the effect of smoking. Finally, if we allow for differences in both observed and unobserved characteristics, the potential mean birthweight of women who aborted would have 140 grams less than the observed 
mean birthweight.

As expected the OLS coefficients of prenatal care delay are negative. That is, the longer a woman delays between conception and her first prenatal care visit, the lighter the infant at birth. In the case of whites, each month of delay reduces birthweight by 4.4 grams, but the coefficient is not significant at the 5 percent level on a one-tailed test. The figure for blacks is 12.4 , which is significant at the 5 percent level. The results for whites are almost identical to the OLS estimates obtained by Rosenzweig and Schultz (forthcoming a) with data on births to women of all races from the 1980 U.S. National Natality Followback Survey. However, Rosenzweig and Schultz emphasize the TSLS estimates which reveal that a month's delay in the initiation of prenatal care decreases birthweight by 91 grams, a twenty-fold increase over the estimates they obtain by OLS.

The results of treating prenatal care as an endogenous input are presented in Table 4. The TSLS estimate for blacks is three times greater than the corfficient obtained by OLS; the TSLS estimate remains statistically significant at the 5 percent level. For whites the coefficient of prenatal care increases six-fold when estimated by TSLS but the null hypothesis of no effect cannot be rejected. Although the direction of the change between the OLS and TSLS estimates is similar to that obtained by Rosenzweig and Schultz, the magnitude of the change is substantially less. Moreover, we find no empirical evidence that prenatal care should be treated as endogenous. ${ }^{21}$ Following Heckman (1980) and later Nakamura and Nakamura (1981), we applied a Wu test in which the residuais from the equation predicting prenatal care corrected for selection were entered as a right-hand-side regressor in the 
birthweight equation. We could not reject the null hypothesis of no correlation in either the white or black specifications at the 5 percent level. The relevant $F$ statistics are presented in Table 4.

A comparison of our results with those of Rosenzweig and Schultz, however, is limited for several reasons. First, our data is restricted to New York City whereas the National Natality Survey samples women from across the country. Furthermore, we were able to estimate a race-specific model which proved to be important. Third, the National Survey excludes out-of-wedlock births. Over 57 percent of all births to black women in the United States and over 70 percent in New York are born out-of-wedlock (U.S. Bureau of the Census 1986). Fourth, given our focus on self-selection, we treated only prenatal care as an endogenous input whereas Rosenzweig and Schultz included age, parity and smoking as endogenous. $^{22}$ Fifth, our specification of the birthweight equation production function included additional inputs such as education, the sex of the newborn, and a measure of the quality of care. In regressions not shown, the omission of education tended to raise the effect of early prenatal care on birthweight. Finally, if the inclusion of lambda controls in part for variations in the endowment as well as the consumption of other endogenous inputs (see section I), then the need for TSLS may be attenuated.

\section{Conclusion}

Recent attempts to obtain structural estimates of the infant health technology have used TSLS to control for adverse selection in input use. In this paper we have presented a model in which the decision to give birth among pregnant women allows for a more general form of self-selection. Because of 
the widespread availability and use of abortion in New York City, women who choose to give birth bring to their pregnancies a set of unobserved factors or behaviors that are associated with the increased consumption of prenatal care and increased birthweight.

We found selection to be race-specific. Only among black women is the decision to give birth correlated with healthy behavior and improved birth outcomes. The result is consistent with the interpretation that the mean shadow price of contraception and the variance in this price are greater for blacks than for whites. This suggests that in areas where abortion availability is limited, holding the price of contraception constant, the selection process encouraged by abortion will be muted. Evidence for that latter has been reported by Corman, Joyce, and Grossman (1987) and Joyce (1987) with county-leve 1 data.

In sum, the findings presented here should be considered preliminary. Although they highlight the relationship between pregnancy resolution and the infant health technology, much more work is needed. First, the model should be tested on national data in which variations in the shadow price of abortion are likely to be greater. Second, better data is needed on why women abort. Rapid advances in fetal diagnoses and the increased spread of perinatal AIDS will tend to encourage more selective abortion. Such trends will emphasize a model in which the health endowment of the women becomes a more important factor in the resolution of pregnancies as well as the incidence of congenital abnormalities among newborns. And finally, the results presented here suggest that important gains in our understanding of birth outcomes and prenatal behavior could come from a model that allows the 
information encapsuled in pregnancy intentions as well as pregnancy resolutions to impact on infant health. This study represents a first step in that direction. 


\section{FOOTNOTES}

* Research for this paper was supported by Grant Number 1 R01 HD24154 from the National Institute of Child Health and Human Development to the National Bureau of Economic Research and by Grant Number 86-3848 from the Henry J. Kaiser Family Foundation to the NBER. We are indebted to the following people for supplying us with data without which this research could not have been undertaken: Jean Lee, Alberto Valentin, and Louise Berenson of the Division of Biostatistics, New York City Department of Health; Stanley Henshaw of the Alan Guttmacher Institute; and Marc Jacobs and Jonah Dtelsberg of the City University of New York Data Service. We are also indebted to Victor Fuchs, Paul Gertler, John Mullahy, Cordelia Reimers, and T. Paul Schultz for helpful comments and suggestions. Finally, we wish to thank Frank Chaloupka, Pamela Mobilia, and Naci Mocan for research assistance. This paper has not undergone the review accorded officlal NBER publications; in particular, it has not been submitted for approval by the Board of Directors. Any opinions expressed in the paper are those of the authors and not those of the NBER, the NICHD, or the Kaiser Foundation.

${ }^{1}$ To control for adverse selection caused by health heterogeneity Rosenzweig and Schultz (1982, 1983a, 1983b, forthcoming a, forthcoming b); Corman, Joyce, and Grossman (1987); and Joyce (1987) use local area prices, parents' income, and parents' education as instrumental variables. If, however, the source of bias is due to omitted endogenous inputs such as nutrition, exercise, and the avoidance of stress, the last two instruments 
may be inappropriate.

2Leibowitz, Eisen, and Chow (1986) and Joyce (1988) study the decision to abort a pregnancy in an economic context. But they do not incorporate this decision into a larger scale model of the optimal number and quality of children and the choice of contraceptive techniques. Moreover, they do not use the information conveyed by the decision to abort or give birth to estimate infant health production functions.

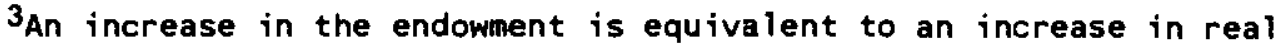
income. Provided all commodities in the utility function are superior, their optimal values rise. We use the tern "very likely" in the text because we do not fully take account of induced substitution between the optimal number of children and their quality (health) that occurs in the model developed by Becker and Lewis (1973).

${ }^{4}$ To the extent that there are measured components of the price of contraception, such as mother's education or the availability of family planning clinics, these components are now included in the $x_{j}$ vector. Similar comments apply to the other variables.

${ }^{5}$ Note that adverse or favorable selection in pregnancy resolution is determined by the sign of correlation between the disturbance term in the birth probability equation and the disturbance term in the birthweight equation. Adverse or favorable selection in input use is determined by the sign of the correlation between the disturbance term in the birthweight equation and the disturbance term in the prenatal care equation. Although the procedure described below does not yield an estimate of $\sigma_{23}$, its sign 
can be inferred from the signs of $\sigma_{12}$ and $\sigma_{13}$ in a single factor model. With more than one factor, the sign of $\sigma_{23}$ can be inferred by placing reasonable restrictions on the magnitudes of certain parameters. For example, suppose that $e$ and a vary while $c$ does not. In addition, suppose that $\sigma_{12}$ is positive. The necessary condition for $\sigma_{23}$ to be negative (which is plausible since $\sigma_{13}$ must be negative) is $\beta_{4} \gamma_{4} \sigma_{e}^{2}<-\beta_{3} \gamma_{3} \sigma_{q a}$. When $\beta_{4}=\beta_{3}$ and $\gamma_{4}=\gamma_{3}$, this is satisfied provided $\sigma_{e}^{2}>-\sigma_{q a}$.

6The above statement is subject to one modification. The case in which the effects of the determinants exactly offset each other $\left(\sigma_{12}=\sigma_{13}=\right.$ $\sigma_{23}=0$ ) cannot be distinguished from one in which each effect taken alone is zero.

${ }^{7}$ This can be illustrated in the context of a simple model in which the following utility function is maximized:

$$
U=U[b(m, a), q, n, s] .
$$

Here $n$ is the number of births and $s$ is adult consumption. Let $p^{\star}$ be the money price of $q$, let the money prices of $m$ and $s$ each equal one dollar, and let a subscript denote a partial derivative. First-order conditions for $m, q, n$, and $s$ are

$$
\begin{aligned}
& U_{b} b_{m}=\mu n \\
& U_{b} b_{q}+U_{q}=\mu p^{\star} \\
& U_{n}=\mu m \\
& U_{s}=\mu,
\end{aligned}
$$

where $\mu$ is the marginal utility of income. Hence

$$
\left(b_{q} / b_{m}\right)=\left[p^{\star}-\left(U_{q} / \mu\right)\right] / n \text {. }
$$

The last equation equates the ratio of marginal products in the production 
of birthweight to the input price ratio. According to this equation, the price of input $q$ is $p^{\star}-\left(U_{q} / \mu\right)$. Clearly, this price is endogenous because $U_{q} / \mu$ depends on the arguments in the utility function. Exogenous determinants of this variable enter the birth probability and prenatal care equations. For example, suppose that the utility function of the $i^{\text {th }}$ family is

$$
u_{i}=b_{i}^{\phi 1}+q_{i}^{\phi} i+n_{i}^{\phi 3}+s_{i}^{\phi} \phi_{i} \text {. }
$$

Then the ratio of $\phi_{2 i}$ to $\phi_{4} i$ serves as an unobservable in birth outcomes.

8 Based on the notation in note 7 , a reduction in the price of an infant health input could reduce the quantity of $b$ or $n$ demanded but not both. This is due to induced substitution between the two variables generated by the endogeneity of their shadow prices (Becker and Lewis 1973; Willis 1973). Of course, both $b$ and $n$ could rise as the price of an infant health input falls. In our context $b$ is unlikely to fall unless $q$ and $m$ are very good substitutes, and this implausible result is ruled out. Even if $\mathbf{n}$ falls with $p$, the probability of giving birth should rise. This is because some of the unobserved factors that cause $p$ to vary are also likely to cause the efficiency and psychic cost of contraception to vary.

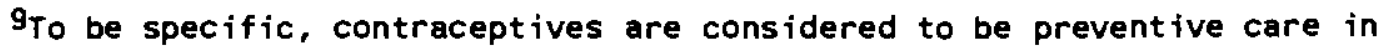
the U.S. and are not covered by most health insurance policies. A second factor is the structure of the U.S. health care system. In other countries women go to one doctor, usually a family practitioner, for all their medical needs. In the U.S. specialists dominate. Women must go to a gynecologist for birth control and have the responsibility for finding a provider. A third factor is that family planning clinics are widely used in other 
countries, but in the U.S. they have the stigma of being primarily directed at poor women. Finally, the amount of contraceptive information provided by schools, radio, television, newspapers, and magazines is more limited in the U.S.

10The two step procedure just described yields consistent, although inefficient, estimates. Efficient estimates can be obtained by maximum likelihood procedures in which the three equations are estimated simultaneously, and the residual covariances $\left(\sigma_{12}\right.$ and $\left.\sigma_{13}\right)$ are obtained directly. The maximum likelihood estimates are not presented in section II I because they were almost identical to the two step estimates with an exogenous prenatal care measure. When prenatal care is treated as endogenous (see below), the likelihood function is too complicated to pursue estimation methods other than the two-stage least squares probit method for simultaneous equations models with selectivity developed by Lee, Maddala, and Trost (1980). For the same reason, we avoid a bivariate probit model with sample selection in which continuous birthweight is replaced by a dichotomous indicator of low birthweight (less than 2,500 grams). In particular, estimation of this model is not feasible when prenatal care is endogenous.

11There were several reasons for choosing New York City. First, only 12 states in the U.S. maintain detailed information on induced abortions as part of their vital registration system (Griner-Powell 1986). Second, the large number of minorities in New York City permitted a race-specific analysis. Third, New York City birth and induced termination certificates contain items that are not recorded in other states -- specifically, how the birth and abortion were financed, whether the procedure was performed 
by the patient's private physician, and whether the pregnancy was complicated by alcohol, drugs, and tobacco.

12 We do not include women whose pregnancies were terminated by spontaneous abortion. Early spontaneous abortions are poorly reported. The New York City Department of Health reported 4,960 spontaneous abortions in 1984. This represented less than 4.4 percent of all live births. Yet, data from the National Survey of Family growth indicate that the ratio of spontaneous abortions to live births is greater than .21 (Pratt et al. 1984).

13 our analysis is race-specific because there are substantial differences in birth outcomes, prenatal behavior, and abortion rates between whites and blacks (Henshaw et a1. 1985; Corman, Joyce, and Grossman 1987). We exclude Hispanics in order to focus on white and black differences and to make our results more comparable to previously published work. Moreover, it has been argued recently that Hispanics should not be lumped together because differences in medical care utilization, birth outcomes, and abortions among, for example, Puerto Ricans, Mexicans, and Cubans are of a nontrivial magnitude (Williams, Binkin, and Clingman 1986; Schur, Bernstein, and Berk 1987; Joyce 1988). We hope to explore these differences in subsequent research.

14 There are 30 health districts in New York City. Each contains approximately 10 health areas.

15In the birth probability equation the method of finance is reduced to two categories, Medicaid and all others. The self-pay category is difficult to interpret in this equation because third-party coverage of abor- 
tions is not common. Among women who give birth, however, third party coverage more accurately reflects a well-insured individual.

${ }^{16}$ That is, a woman gives birth if her optimal number of children is less than or equal to parity plus one. Both the optimal number of children and parity (which for a given family size measures the timing and spacing of births) are governed by command over resources, prices, efficiency, tastes, marital status, and mother's age.

17 our results were not sensitive to these identification restrictions.

${ }^{18}$ For instance, the price of cigarettes varies considerably among states due primarily to differences in state excise tax rates on cigarettes. Our cigarette measure also is difficult to endogenize because it is dichotomous and pertains to pregnancies complicated by smoking rather than to the quantity smoked while pregnant. Both these characteristics also apply to the alcohol and narcotics variables, while the indicator of the quality of medical care (delivery by the woman's private physician) is dichotomous.

${ }^{19}$ Although our measure of cigarette smoking is a dichotomous indicator, the 187 gram differential is almost identical to that estimated by Rosenzweig and Schultz (forthcoming a) in the 1980 National Natality Survey.

20 Based on equations (10) and (11) in the text, mean birthweight in the birth sample $\left(b_{b}\right)$, potential mean birthweight for women who abort $\left(b_{a}\right)$, and the mean values of prenatal care in each sample ( $m_{b}$ and $m_{a}$, respectively) can be written

$$
b_{b}=\beta_{1} x_{b}+\beta_{2} m_{b}+\left(\sigma_{12} / \sigma_{1}\right) \lambda_{b}
$$




$$
\begin{aligned}
& b_{a}=\beta_{1} x_{a}+\beta_{2} m_{a}+\left(\sigma_{12} / \sigma_{1}\right) \lambda_{a} \\
& m_{b}=\gamma_{1} y_{b}+\left(\sigma_{13} / \sigma_{1}\right)_{b} \\
& m_{a}=\gamma_{1} y_{a}+\left(\sigma_{13} / \sigma_{1}\right)^{\lambda} a .
\end{aligned}
$$

Here $x_{b}, y_{b^{\prime}} x_{a}$, and $y_{a}$ are the means of the determinants of birthweight and prenatal care in each sample, $\lambda_{b}$ is the mean of the inverse of Mill's ratio in the birth sample and $\lambda_{a}$ is the mean of the inverse of Mill's ratio, defined as $-f\left(Q_{j}\right) /\left[1-F\left(Q_{i}\right)\right]$, in the abortion sample. Thus, the mean birthweight difference between those who gave birth and those who aborted had they instead given birth is:

$$
b_{b}-b_{a}=\beta_{1}\left(x_{b}-x_{a}\right)+\beta_{2}\left(m_{b}-m_{a}\right)+\left(\sigma_{12} / \sigma_{1}\right)\left(\lambda_{b}-\lambda_{a}\right) \text {. }
$$

The last term in this equation is positive given $\sigma_{12}>0$. It also represents the difference in birthweight due to unobserved factors. The first two terms to the right of the equal sign capture the differences due to observed characteristics. It should be noted that some of the variables in the $x_{b}$ vector were not observed for women who aborted. Thus, to calculate the mean potential birthweight of women who aborted we assumed that the proportion of women who used tobacco, drugs and alcohol as well as the proportion male infants and the proportion of women served by private physicians were the same between the two samples. To test the sensitivity of our results to this assumption, we re-estimated the model excluding these five variables from the birthweight equation. The difference between the observed mean and the potential mean birthweight was not altered appreciably.

21 The reader is reminded that this result is specific to a model which controls for self selection into the birth sample.

22To make our results more comparable to those of Rosenzweig and Schultz 


$$
\text { F }-9
$$

we excluded parity, age and legitimacy status from the demand for prenatal care. The omission had negligible effect on the TSLS estimates. 
Becker, Gary S. "A Theory of the Allocation of Time." Economic Journal 75 (September 1965): 493-517.

Becker, Gary S., and Lewis, H. Gregg. "On the Interaction between the Quantity and Quality of Children." Journal of Political Economy 81 (March/April 1973): S274-S288.

Bureau of the Census, U.S. Department of Commerce. Statistical Abstract of the United States. Washington, D.C.: U.S. Government Printing office, 1986.

Corman, Hope, and Grossman, Michael. "Determinants of Neonatal Mortality Rates in the U.S.: A Reduced Form Mode1." Journal of Health Economics 4 (September 1985): 213-236.

Corman, Hope; Joyce, Theodore J.; and Grossman, Michael. "Birth Outcome Production Functions in the U.S." Journal of Human Resources 22 (Summer 1987): $339-360$.

Edwards, Linda N., and Grossman, Michael. "Adolescent Health, Family Background, and Preventive Medical Care." In Research in Human Capital and Development, Volume 3, edited by David Salkever, Ismail Sirageldin, and Alan Sorkin. Greenwich, Connecticut: JAI Press, Inc., 1983.

Forrest, Jacqueline Darroch. "The Delivery of Family Planning Services In the United States." Family Planning Perspectives 20 (March/Apri) 1988): $88-98$

Forrest, Jacquel ine Darroch, and Fordyce, Richard R. "U.S. Women's 
Contraceptive Attitudes and Practice: How Have They Changed in the 1980s?" Famfly Planning Perspectives 20 (March/April 1988): 112-118. Gortmaker, Steven L. "Poverty and Infant Mortality in the United States." American Sociological Review 44 (April 1979): 280-297. Grossman, Michael. "The Economics of Joint Production in the Household." Report 7145, Center for Mathematical Studies in Business and Economics, University of Chicago, September 1971.

Grossman, Michael. "On the Concept of Health Capital and the Demand for Health." Journal of Political Economy 80 (March/April 1972): 223-255. Hausman, Jerry A. "Specification Tests in Econometrics." Econometrica 46, (November 1978): 1251-71.

Heckman, James J. "Sample Selection Bias as a Specification Error." Econometrica 47 (January 1979): 153-161.

Heckman, James J. "Sample Selection Bigs as a Specification Error with an Application to the Estimation of Labor Supply Functions. In Female Labor Supply, edited by James P. Smith. Princeton, New Jersey: Princeton University Press, 1980.

Heckman, James $\mathrm{J} .$, and Willis, Robert J. "Estimation of a Stochastic Model of Reproduction: An Econometric Approach." In Household Production and Consumption, edited by Nestor E. Terlecky. New York: National Bureau of Economic Research, 1975. Henshaw, Stanley K.; Binkin, Nancy J.; Blaine, Ellen; and Smith, Jack C. "A Portrait of American Women who Obtain Abortions." Family Planning Perspectives 17 (March/Apri1 1985): 90-96. Hofferth, Sandra L. "Teenage Pregnancy and its Resolution." In Risking 
The Future: Adolescent Sexuality, Pregnancy, and Childbearing, edited by National Research Council, Vol. II. Washington, D.C.: National Academy Press, 1987 .

Hogue, Carol J.R.; Cates, Willard, Jr.; and Tietze, Carol. "The Effects of Induced Abortion on Subsequent Reproduction." Epidemiologic Review 4 $(1982): 66-94$

Hotz, V. Joseph, and Miller, Robert A. "An Empirical Analysis of Life Cycle Fertility and Female Labor Supply." Econometrica 56 (January $1988): 91-118$.

Institute of Medicine. Preventing Low Birthweight. Washington, D.C.: National Academy Press, 1985.

Jones, Elise F.: Forrest, Jacqueline D.; Henshaw, Stanley K.; Silverman, Jane; and Torres, Aida. "Unintended Pregnancy, Contraceptive Practice And Family Planning Services In Developed Countries." Family Planning Perspectives 20 (March/April 1988) 53-67.

Joyce, Theodore J. "The Impact of Induced Abortion on Black and White Birth Outcomes in the United States." Demography 24 (May 1987): 229-244.

Joyce, Theodore J. "The Social and Economic Correlates of Pregnancy Resolution Among Adolescents in New York City by Race and Ethnicity:

A Multivariate Analysis." American Journal of Public Health 78 (June 1988): 626-631.

Lee, Lung-Fei; Maddala, G.S.; and Trost, Robert P. "Asymptotic Covariance Matrices at Two-Stage Probit and Two-Stage Tobit Methods for Simultaneous Equations Models with Selectivity." Econometrica 48 (March 1980): 491-499. 
Leibowitz; Arleen; Eisen, Marvin; and Chow, Winston K. "An Economic Model of Teenage Pregnancy Decision-Making." Demography 23 (February 1986): $67-77$.

Michae 1, Robert T., and Becker, Gary. S. "On the New Theory of Consumer Behavior." Swedish Journal of Economics 75 (1973): 378-396.

Michael, Robert T. "Education and the Derived Demand for Children." Journal of Political Economy 81 (March/April 1973): S128-S164.

Michael, Robert T. The Effect of Education on Efficiency in Consumption. New York: Columbia University Press for the National Bureau of Economic Research, 1972.

Michael, Robert T., and Willis, Robert J. "Contraception and Fertility: Household Production Under Uncertainty." In Household Production and Consumption, edited by $N$. Terlecky. New York: National Bureau of Economic Research, 1975.

Nakamura, Alice, and Nakamura, Masao. "On the Relationships Among Several Specification Error Tests Presented By Durkin, Wu, and Hausman." Econometrica 49 (November 1981): 1583-1588.

D'Conne 11, Martin, and Rogers, Carolyn C. "Dut-of-Wedlock Births, Premarital Pregnancies and Their Effect on Family Formation and Dissolution." Family Planning Perspectives 16 (July/August 1984): $157-162$

Pollack, Robert A., and Wachter, Michael L. "The Relevance of the Household Production Function and Its Implications for the Allocation of Time." Journal of Political Economy 83 (April 1975): 255-277. Pratt, William F.; Mosher, William D.; Bachrach, Christine A.; and Horn, 


$$
\mathbf{R}-\mathbf{5}
$$

Marjorie C. "Understanding U.S. Fertility: Findings from the National Survey of Family Growth, Cycle III." Population Bulletin 39, 1984.

Rosenzweig, Mark R., and Schuitz, T. Paul. "Consumer Demand and Househoid Production: The Relationship Between Fertility and Child Mortality." American Economic Review 73 (May 1983) 38-42. (a)

Rosenzweig, Mark R., and Schuitz, T. Paul. "Education and Household Production of Child Health." Proceedings of the American Statistical Association, Social Statistics Section. Washington, D.C.: American Statistical Association, 1981.

Rosenzweig, Mark R., and Schultz, T. Paul. "Estimating a Household Production Function: Heterogeneity, the Demand for Heaith Inputs, and Their Effects on Birth Weight." Journal of Political Economy 91 (October 1983) 723-746. (b)

Rosenzweig, Mark R., and Schuitz, T. Paul. "The Behavior of Mothers as Inputs to Child Heaith: The Determinants of Birth Weight, Gestation, and Rate of Retal Growth." In Economic Aspects of Health, edited by Victor R. Fuchs. Chicago: University of Chicago Press for the National Bureau of Economic Research, 1982.

Rosenzweig, Mark R., and Schuitz, T. Paul. "The Stability of Household Production Technology: A Replication." Journal of Human Resources, for thcoming. (a)

Rosenzweig, Mark R., and Schultz, T. Paul. "Who Receives Medical Care? Income, Implicit Prices and the Distribution of Medical Services Among Pregnant Women in the United States." American Economic Review, for thcoming. (b) 
Schur, Claudia L.; Berstein, Amy B.; and Bork, Marc L. "The Importance of Distinguishing Hispanic Subpopulations in the Use of Medical Care." Medical Care 25 (July 1987): 627-641.

Stephen, Elizabeth Hervey; Rindfuss, Ronald R.; and Bean, Frank 0. "Racial Differences in Contraceptive Choice: Complexity and Implications." Demography 25 (February 1988): 53-70.

We lch, Finis. "Education in Production." Journal of Political Economy 78 (January/February 1970): 35-59.

Williams, Ronald; Binkin, Nancy J.; and Clingman, Elizabeth J. "Pregnancy Outcomes Among Spanish-surname Women in California." American Journal of Public Health 76 (April 1986): 387-391.

Willis, Robert J. "A New Approach to the Economic Theory of Fertility Behavior." Journal of Political Economy 81 (March/April 1973): S14-S64. Wozniak, Gregory 0. "Human Capital, Information, and the Early Adoption of New Technology." Journal of Human Resources 22 (Winter 1987): 101-112. Wu, De-Min. "Alternative Tests of Independence Between Stochastic Regressors and Disturbances." Econometrica 41 (July 1973): 733-750. 